\title{
Detection of Giardia cysts in sewage and estimations of giardiasis prevalence among inhabitants in Hyogo Prefecture, Japan
}

\author{
TAKUYA ODA ${ }^{\dagger}$, MASATO KAWABATA $^{\dagger}$, and SHOJI UGA ${ }^{\ddagger}$ \\ Accepted 11, January, 2005
}

\begin{abstract}
We recovered Giardia cysts from sewage and estimated the prevalence of giardiasis among inhabitants in Hyogo Prefecture, western Japan. Two 200-ml sewage samples were collected once a month from two different sewage plants (A and B) during a one-year period. After pretreating the samples by filtration and centrifugation in the presence of alcohol and diethyl ether, an immunomagnetic separation method was applied to isolate Giardia cysts. The mean number of cysts recovered from plants A and B were 880/L and 2,000/L, respectively. Circadian rhythms in the number of cysts detected on each of two examination days were observed with a peak at 10:00 a.m., and seasonal variations in cyst numbers were also observed with two peaks in May and December. By using the data obtained from this survey, we estimated that the prevalence of Giardia infection in habitants in the areas serviced by plants A and B were $0.1-1.1$ and $0.1-1.3 \%$, respectively.
\end{abstract}

Key Words: Giardia intestinalis, sewage, detection method, prevalence

\section{INTRODUCTION}

The flagellate protozoan parasite Giardia intestinalis is widely distributed throughout the world with a high prevalence in developing countries in the tropics and subtropics. G. intestinalis infection is acquired by digesting cysts excreted from infected humans and animals [1]. Approximately 20 to $30 \%$ of inhabitants in developing countries in Asia and Africa are infected with this parasite. In developed countries with improved hygiene conditions, meanwhile, Giardia infection also constitutes a public health concern [2]. In developed countries, the parasite is brought back from abroad by infected travelers [3]. Many outbreaks of giardiasis due to ingestion of inadequately treated water have also occurred in developed countries; five of these occurred in the United States in 1993 and 1994 [4]. Although a direct smear method is frequently used to detect Giardia cysts in stool samples, it does not consistently reflect the accurate prevalence of giardiasis in a given survey area. For instance, 15 to $20 \%$ of patients are reportedly diagnosed as false negative [5], despite the use of appropriate fecal examinations. The need for examination of three consecutive stool samples has therefore been indicated for accurate diagnosis [6,7].

The reported prevalence of giardiasis in the metropolis and Tokai regions of Japan ranges from $0.2-0.9 \%[8,9]$.
However, the study populations consisted of outpatients and /or inpatients who might not have represented the total population in the area. Furthermore, it is time consuming and expensive to examine thousands of individuals, and it is difficult to obtain consent for stool surveys.

Sykora $e t$ al. examined 11 sewage plants at different cities in the USA and detected 642 to 3,375 Giardia cysts per liter of samples [10], and Jakubowski et al. used these data to clarify the relationship between cyst number and prevalence in the respective cities [11]. Although these studies are interesting from the viewpoint of simplicity and/or economy, they do not discuss the recovery efficiency of their method or the circadian rhythm of cyst numbers. In this study, we recovered Giardia cysts from sewage samples using the immunomagnetic separation method at a fixed time each month and used the results to estimate the prevalence of the intake of Giardia infection among inhabitants in Hyogo Prefecture, Japan.

\section{MATERIALS AND METHODS}

\section{Sewage Plants}

The present survey was conducted at two different sewage treatment plants (A and B) in Hyogo Prefecture, Japan, during a one-year period (July 2002 to September 2003). Plant $A$ is located on an $44 \times 10^{5}-\mathrm{m}^{2}$ artificial island

\footnotetext{
${ }^{\dagger}$ International Center for Medical Research and Treatment, Kobe University School of Medicine, 7-5-1 Kusunoki-cho, Chuo-ku, Kobe 650-0017, and ${ }^{\ddagger}$ Department of Medical Technology, Faculty of Health Sciences, Kobe University School of Medicine, 7-10-2 Tomogaoka, Suma-ku, Kobe 654-0142, Japan
} 
constructed in 1981 in the southern part of the prefecture. Approximately $15 \times 10^{3}$ people live on this island, and plant A treats only the sewage from this population. There are dogs and cats but no large animals on the island. On the other hand, plant B is located $22 \mathrm{~km}$ west of plant A and treats the sewage of approximately $205 \times 10^{3}$ people. Many livestock animals such as cows, chickens and pigs are bred in this area. The mean daily flow of plants A and B during the study period was $8 \times 10^{6}$ and $66 \times 10^{6} \mathrm{~L}$, respectively.

\section{Sample Collection and Concentration}

Two hundred $\mathrm{ml}$ of sewage was collected from each plant at 10:00 a.m. once a month for one year. Samples were placed in 250-ml conical tubes into which $2 \mathrm{ml}$ of $10 \%$ gelatin solution was added to effectively disperse the substances. The tubes were then capped tightly and their contents mixed thoroughly. In an additional experiment, samples were collected from plant A every two hours for 24 hours to clarify the hourly changes in cyst number. We repeated this experiment twice, on May 28 and August 12, 2003. In addition, sampling was performed for 5 continuous days in plant A to compare cyst number before (April 14-18, 2003) and after the holiday week (May 12-16, 2003).

The sewage sample was filtered through a stainless steel sieve with $32 \mu \mathrm{m}$ pores, then centrifuged at $1,000 \times \mathrm{g}$ for $10 \mathrm{~min}$. The supernatant was aspirated leaving $4 \mathrm{ml}$ of concentrate in the tube into which $4 \mathrm{ml}$ each of ethyl alcohol and diethyl ether were added (total $12 \mathrm{ml}$ ). The samples were then mixed and incubated at $60^{\circ} \mathrm{C}$ for $5 \mathrm{~min}$. After fur- ther mixing, the contents were centrifuged at $1,000 \times \mathrm{g}$ for $10 \mathrm{~min}$, then the pellet was re-suspended in $15 \mathrm{ml}$ of $0.1 \%$ gelatin solution and centrifuged again under the same conditions. Finally, the pellet was suspended in $10 \mathrm{ml}$ of distilled water (Fig. 1).

\section{Separation Procedure and Counting of Cysts}

Giardia cysts suspended in the 10-ml water sample were purified using an immunomagnetic separation (IMS) method. In brief, samples were incubated with paramagnetic beads (Dynabeads, Dynal, Oslo, Norway) which were coated with antibodies raised against Giardia. The resulting complex of cysts and beads was then magnetically isolated and washed. The cysts were then dissociated from the beads, and the beads magnetically removed from the purified sample. The cysts were placed in a well-slide and stained using a fluorescein-labeled monoclonal antibody (EasyStain, Biotechfrontiers, North Ryde, Australia) then observed under a fluorescent microscope (BX50, Olympus, Tokyo, Japan). Round or oval fluorescein isothiocyanate (FITC)labeled objects measuring $7-10 \times 12-15 \mu \mathrm{m}$ with two or more internal characteristic features (2-4 nuclei, median bodies, axonemes) were counted as Giardia cysts.

\section{RESULTS}

The recovery efficiency of this method was calculated by spiking one hundred Giardia cysts labeled with red fluorescent dye (Colorseed, Biotechfrontiers, North Ryde, Aus-

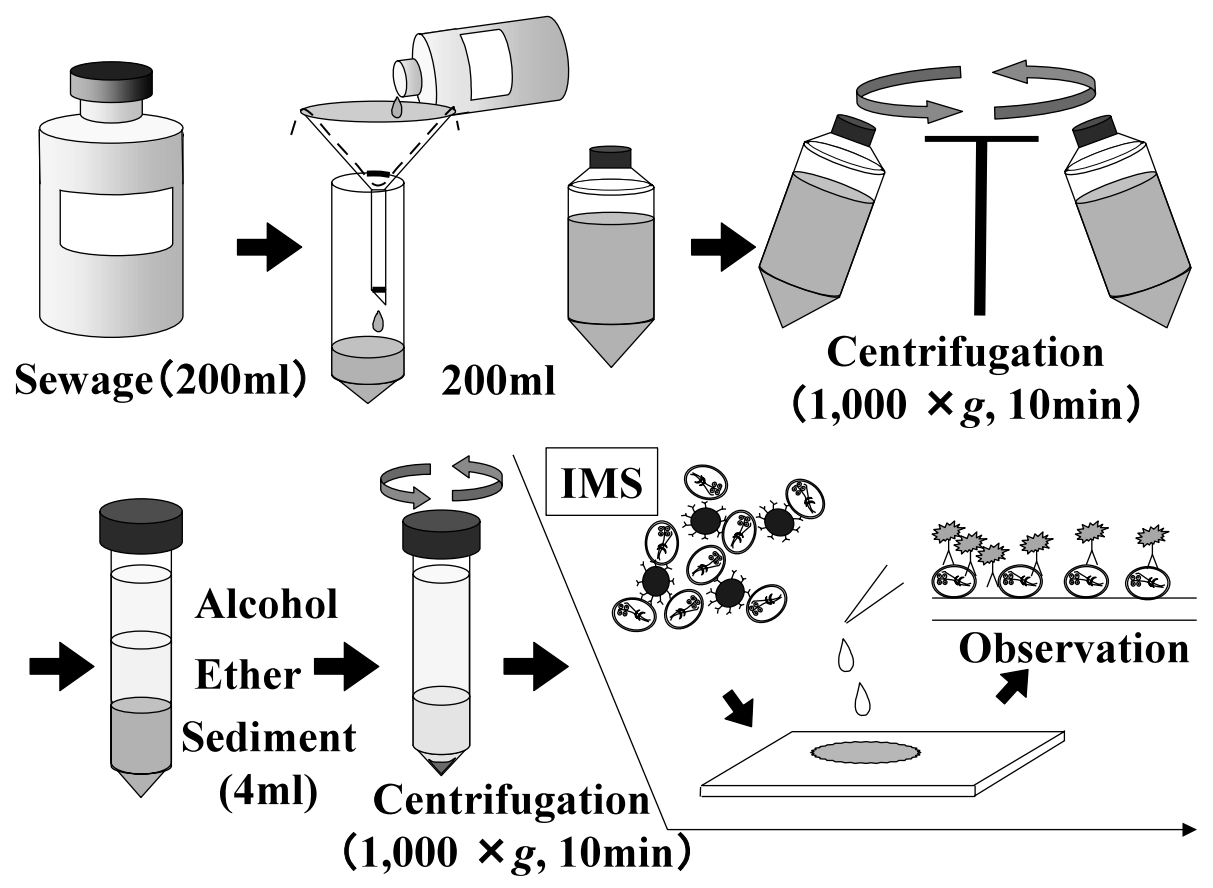

Fig. 1 Method for recovery of Giardia cysts from sewage. 


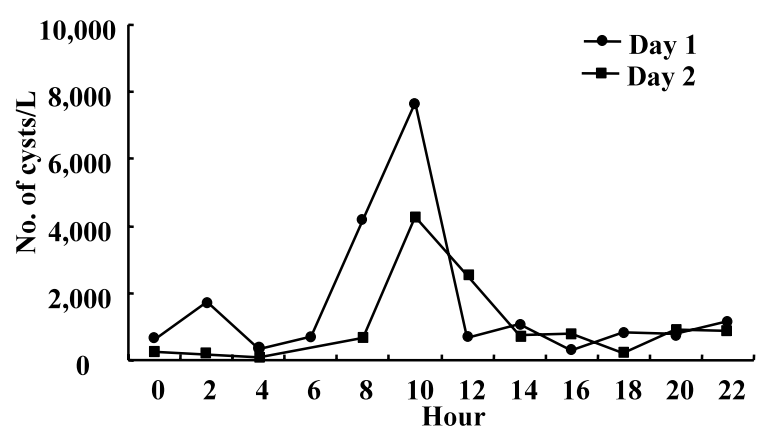

Fig. 2 Hourly change in number of Giardia cysts in relation to sampling time. Sewage samples were examined on May 28 (Day 1) and August 12 (Day 2).

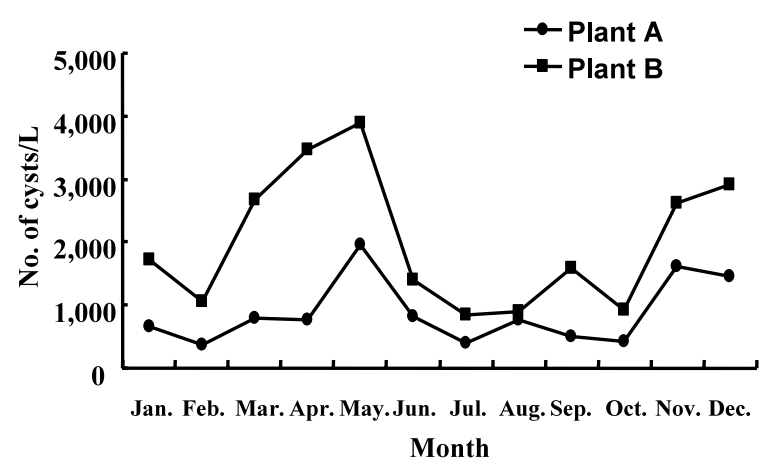

Fig. 3 Monthly change in number of Giardia cysts recovered from each plant. Plant A $(\mathbf{)})$ is located on an artificial island and Plant B $(\boldsymbol{\square})$ is located in the suburbs.

tralia) into 200-ml sewage samples from plant A; this spiking procedure was repeated three times. The average recovery efficiency was calculated as $40 \%(37,42,40, n=3)$ and the number of cysts per liter of sewage sample was corrected according to this recovery efficiency.

Circadian rhythms in cyst numbers in plants $\mathrm{A}$ and $\mathrm{B}$ were observed, with a peak at 10:00 a.m. (4,300/L and 7,700/L, respectively) (Fig. 2). The average number of cysts was $1,700 / \mathrm{L}$ and $1,000 / \mathrm{L}$, respectively). The ratio of cyst number at 10:00 a.m. to the daily average cyst number was 0.22 and 0.24 respectively, and the mean was 0.23 .

Monthly investigation samplings were performed at 10:00 a.m.; therefore, cyst numbers were adjusted to the

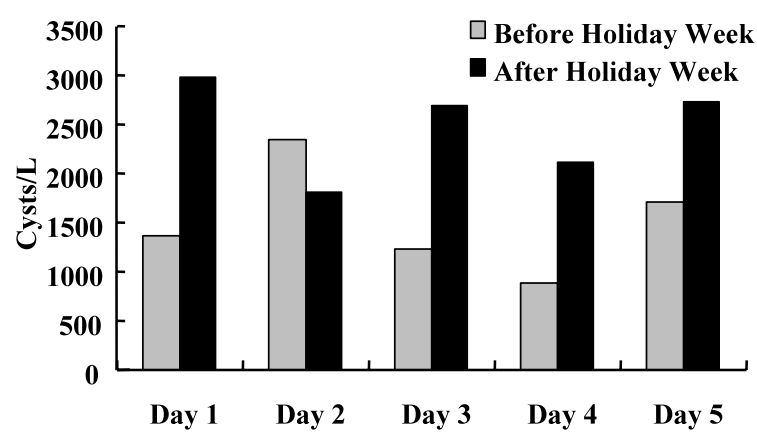

Fig. 4 Comparison between number of Giardia cysts before and after a holiday week. Sewage samples were collected for 2 series of 5 continuous days from April 14 to April 18 (before holiday week: $\square$ ) and from May 12 to May 16 (after holiday week: $\mathbf{\square}$ ).

daily average number. The daily average number of cysts in each examination was equal to the cyst number detected $x$ correction factor $(0.23$; the correction factor is the coefficient used to correct the number of cysts obtained from the 10:00 a.m. sampling period to the daily average).

The seasonal variation in cyst numbers is shown in Fig. 3. The present study revealed that both of the sewage plants studied were positive for Giardia cysts, with a mean number of 880/L (range: $370-2,000 / \mathrm{L}$ ) and 2,000/L (range: 850 - 3,900/L) in plants A and B, respectively. Cysts were detected throughout the year in both plants, with the number of cysts detected in plant B being higher than that in plant A. Monthly changes in the number of cysts recovered from plants A and B showed two peaks, in one May and the other in December. The number of cysts detected after a holiday week was higher than that before: the average number detected before and after was $1,500 / \mathrm{L}$ and $2,500 / \mathrm{L}$, respectively, and the difference was significant ( $<<0.05$ student's $t$ test) (Fig. 4).

The estimated number of infected individuals on each of the examination days was the daily sewage flow $\times$ cyst number of each monthly examination / number of cysts excreted by a patient in one day ( 1 to $2 \times 10^{8}$; according to Tsuchiya, 1931); the estimated prevalence was the estimated number of infected individuals / population in each

Table 1. Estimation of prevalence of giardiasis on examination days in areas covered by plant A and B

\begin{tabular}{|c|c|c|c|c|c|}
\hline \multirow{2}{*}{ Plant } & \multirow{2}{*}{$\begin{array}{l}\text { Quantity of sewage } \\
\text { treated /day }(\mathrm{L})^{*}\end{array}$} & \multirow{2}{*}{$\begin{array}{l}\text { Number of cysts found } \\
(\mathrm{L}) * *\end{array}$} & \multirow{2}{*}{ Population } & \multicolumn{2}{|c|}{ Estimated } \\
\hline & & & & number of patients & prevalence $(\%)$ \\
\hline A & $8 \times 10^{6}$ & $\begin{array}{r}370 \text { (min.) } \\
880 \text { (ave.) } \\
2000 \text { (max.) }\end{array}$ & $15 \times 10^{3}$ & $\begin{array}{rr}15- & 30 \\
35- & 70 \\
80- & 160\end{array}$ & $\begin{array}{l}0.1-0.2 \\
0.2-0.5 \\
0.5-1.1\end{array}$ \\
\hline B & $66 \times 10^{6}$ & $\begin{array}{r}850 \text { (min.) } \\
2000 \text { (ave.) } \\
3900 \text { (max.) }\end{array}$ & $205 \times 10^{3}$ & $\begin{array}{r}280-560 \\
650-1300 \\
1300-2600\end{array}$ & $\begin{array}{l}0.1-0.3 \\
0.3-0.6 \\
0.6-1.3\end{array}$ \\
\hline
\end{tabular}

Estimated number of patients $=* \times * * /$ number of cysts excreted per patient per day ( 1 to $2 \times 10^{8}$, according to Tsuchiya, 1931) Estimated prevalence=estimated number of patients / population in each plant area. 
plant area.

The prevalence of giardiasis in the areas serviced by plants A and B was estimated using the above results (Table 1 ). Consequently, the average monthly prevalence was 0.1 1.1 and $0.1-1.3 \%$, respectively.

\section{DISCUSSION}

Giardia is widely distributed throughout the world with a varying rate of prevalence [2], and it is one of the most common enteric parasites recovered from humans, especially in tropical areas. However, it has become difficult even in these areas, to obtain consent to sample fecal materials. In the U.S.A., attempts have been made to detect Giardia cysts in sewage and to estimate giardiasis prevalence [11], but the sucrose floatation and Lugol's iodine techniques used are relatively insensitive. For instance, using the sucrose flotation technique, Sykora et al. found highly variable results (0.4 to $77.8 \%$ ) with a mean of $11.0 \%$ [10]. With this in mind, we used a modified immunomagnetic bead method [12] to detect Giardia in sewage samples. As a result, the average recovery efficiency from 200-ml of spiked sewage samples was $40 \%$ and estimations of cyst concentrations were more precise.

We observed marked seasonal variations in Giardia cyst recovery, with two peaks in the cold (December) and wetter seasons (May), in this study. These findings were consistent with previous results. For example, among Guatemalan children, the incidence of giardiasis was highest during the cooler and wetter months [13]. Furthermore, in Saudi Arabia, the highest incidence occurred during September, which is the wettest month of the year [14]. Therefore, cyst numbers in sewage might be related to climatic conditions. Jarroll et al. also suggested that Giardia cysts find cooler and wetter conditions more favorable for survival [15].

In the present study, the number of cysts detected after a holiday week exceeded those detected before that week. This finding observed might be related to the Japanese life style, that is, many Japanese take vacations from the end of April to the middle of May and travel to foreign countries, including developing countries, and this custom is also seen at the end of the year. It is possible therefore those individuals are infected during these overseas trips, especially during trips to endemic areas. The present findings correlated well with the holiday period in 2003 (April 29 to May 9). According to the Immigration Bureau, 570,000 Japanese traveled overseas during May 2003, and of these, approximately 230,000 traveled to developing countries. This suggests that 290 of the inhabitants in the area around plant A traveled to developing countries.
Kimura et al. examined Japanese travelers who visited Nepal and India for more than 10 days and who experienced diarrhea when they arrived back in Japan [16]. Their survey revealed that 69 out of $692(9 \%)$ travelers were positive for Giardia cysts. Giardia is the most common enteric protozoan parasite in Nepal and India $[17,18,19,20]$ and has remained top of the list for the past decade [17]. Similar imports of Giardia infections into developed countries have been reported elsewhere [3]. The reported Giardia cyst shedding rates in calves ranges from 80 [21] to $100 \%$ [22] in British Columbia, Canada. However, since the area serviced by plant $\mathrm{A}$ is an isolated artificial island where livestock are not bred, we can rule out the possibility of sewage contamination by such animals. The hourly variation results obtained in this study also clearly demonstrated that cyst concentrations are related to human activity, and the findings strongly suggest that the Giardia cysts were excreted from inhabitants of this island. This result agrees with the earlier study of Gassmann and Scwartzbrod who suggested that a peak of Giardia cysts was observed at 10:00 a.m. in Nancy, France [23].

It is difficult to assess the number of cysts excreted daily from observations of a single infected individual. Therefore, we calculated the number of infected individuals based on the recovery efficiency, monthly survey, and variation in cyst numbers at different sampling times. Tsuchiya calculated that the number of cysts excreted from an individual/day varied from $0-7 \times 10^{8}$ with cyst-excreting and non-excreting days occurring alternatively during the course of infection [24]. Using this data as a base, we estimated the mean number of cysts excreted per day per patient. Accordingly, the mean number of cysts excreted for a period of during six weeks after the onset of symptoms was $1 \times 10^{8}$, but when calculations were conducted using only the cystexcreting days the value was $2 \times 10^{8}$.

The infection rate of Giardia in the areas serviced by plants A and B was estimated as 0.1-1.1 and 0.1-1.3\%, respectively, and these results were consistent with the results obtained from fecal examinations in Japan (0.2-0.9\%) [8,9]. This study revealed that sewage samples can be used to estimate giardiasis in a particular service area (community) using the IMS method. The method developed for this survey was easy, cost-effective and time saving, and it allowed for accurate estimations of the prevalence of giardiasis. We believe it can be used for future surveys of the prevalence of giardiasis in other areas.

\section{REFERENCES}

1 ) Meyer EA, Jarroll EL. Giardiasis. Am. J. Epidemiol. 1980; 111: 1-12. 
2 ) Rabbani GH, Islam A. Giardiasis in humans: Populations most at risk and prospects for control, in: Thompson RCA, Reynoldson JA, Lymbery AJ, (Eds), Giardia: From Molecules to Disease. CAB International., Wallingford, UK, 1994; 217-249.

3 ) Lopez CE, Juranek DD, Sinclair SP, Schultz MG. Giardiasis in American travelers to Madeira Island, Portugal. Am. J. Trop. Med. Hyg. 1978; 27: 1128-1132.

4 ) Marshall MM, Naumovitz D, Ortega Y, Sterling CR. Waterborne Protozoan Pathogens. Clin. Microbiol. Rev. 1997; 10: 67-85.

5 ) Manson B, Apted. Manson's Tropical Diseases 18 th ed. Bailliere Tindall. London: 1982; 121-145.

6 ) Meyer EA, Radulescu S. Giardia and Giardiasis. Adv. Parasit. 1979; 17: 1-47.

7 ) Wolfe MS. Giardiasis. Pediatr. Clin. N. Am. 1979; 26: 295 $-303$.

8 ) Ichizawa T, Kato H, Mochizuka I, Kurita M, Senoh K, Suzuki N. Giardiasis in Fujieda and its neighboring towns, Shizuoka Prefecture. Jpn. J. Trop. Med. Hyg. 1990; 18: 333-339 (in Japanese).

9 ) Morimoto N, Korenaga M, Komatsu C, Morita M, Sugihara S, Saika K, Nishida M, Sasaki M, Hashiguchi Y. Giardia-infection among subjects revealed diarrhea or passage of soft stool in Kochi Prefecture, Japan. Jpn. J. Trop. Med. Hyg. 1998; 26: 113-116.

10) Sykora JL, Sorber CA, Jakubowski W, Casson LW, Gavaghan PD, Shapiro MA, Schott MJ. Distribution of Giardia cysts in wastewater. Water Sci. Technol. 1991; 24: 187-192.

11) Jakubowski W, Sykora JL, Sorber CA, Casson LW, Gavaghan PD. Determining giardiasis prevalence by examination of sewage. Water Sci. Technol. 1991; 24: 173178.

12) US Environmental Protection Agency. Method 1623: Cryptosporidium and Giardia in water by Filtration/IMS/ FA. Office of Water, EPA-821-R-01-025 2001.

13) Farthing MJG, Mata L, Urrutia JJ, Kronmal RA. Natural history of Giardia infection of infants and children in rural Guatemala and its impact on physical growth. Am. J. Clin. Nutr. 1986; 43: 395-405.

14) Kasim AA, Elhelu MA. Giardiasis in Saudi Arabia. Acta Trop. 1983; 40: 155-158
15) Jarroll EL, Bingham AK, Meyer EA. Giardia cyst destruction: effectiveness of six small quantity water disinfection methods. Am. J. Trop. Med. Hyg. 1980; 29: 8-11.

16) Kimura A, Minekawa Y, Ikeda N, Shimoirisa K, Kusui Y, Mastumoto Y, Nakabayashi T. Survey of Giardia lamblia infection in returning travelers with diarrhoea from India and Nepal at Osaka airport quarantine station. Jpn. J. Trop. Med. Hyg. 1992; 20: 291-297 (in Japanese).

17) Rai SK, Bajracharya K, Budhathoki S, Khadka JB, Rai KK, Shrestha MK, Sharma CM, Nakanishi M, Kubo T, Shrestha HG. Status of intestinal parasitoses at TU Teaching Hospital. J.Insti. Med. (Nepal) 1995; 17: 13442.

18) Rai SK, Hirai K, Abe A, Ishiyama S, Rai G, Ono K, Uga S. Intestinal parasitoses among school children in a rural hilly area of Dhading district, Nepal. Npl. Med. Coll. J. 2002; 4: 54-8.

19) Ono K, Rai SK, Chikahira M, Fujimoto T, Shibata H, Wada Y, Tsuji H, Oda Y, Rai G, Shrestha CD, Masuda K, Shrestha HG, Matsumura T, Hotta H, Kawamura T, Uga S. Seasonal distribution of enteropathogens detected from diarrheal stool and water samples collected in Kathmandu, Nepal. Southeast Asian J. Trop. Med. Public Health 2001; 32: 520-6.

20) Fernandez MC, Verghese S, Bhuvaneswari R, Elizabeth SJ, Mathew T, Anitha A, Chitra AK. A comparative study of the intestinal parasites prevalent among children living in rural and urban settings in and around Chennai. J. Commun. Dis. 2002; 34: 35-39.

21) Olson ME, Guselle NJ, O'Handley RM, Swift ML, McAllister TA, Jelinsk MD, Morck DW. Giardia and dairy calves in British Columbia. Can. Vet. J. 1997; 38: 703706.

22) Ralston BJ, McAllister TA, Olson ME. Prevalence and infection pattern of naturally acquired giardiasis and cryptosporidiosis in range beef calves and their dams. Vet. Parasitol. 2003; 114: 113-122.

23) Gassmann L, Schwartzbrod J. Wastewater and Giardia cysts. Water Sci. Technol. 1991; 24: 183-186.

24) Tsuchiya H. A study on variabilities in dimensions and numbers of discharged cysts Giardia lamblia (stiles 1915) from day to day under normal conditions. Am. J. Hyg. 1931; 13: 544-567. 